\title{
BMJ Open The impact of duty cycle workflow on sign-out practices: a qualitative study of an internal medicine residency program in Maryland, USA
}

Soo-Hoon Lee, ${ }^{1}$ Sanjay V Desai, ${ }^{2}$ Phillip H Phan ${ }^{3}$

To cite: Lee S-H, Desai SV, Phan PH. The impact of duty cycle workflow on sign-out practices: a qualitative study of an internal medicine residency program in Maryland, USA. BMJ Open 2017;7:e015762. doi:10.1136/ bmjopen-2016-015762

- Prepublication history and additional material are available. To view please visit the journal (http://dx.doi.org/ 10.1136/ bmjopen-2016-015762)

Received 29 December 2016 Revised 15 March 2017 Accepted 31 March 2017
CrossMark

${ }^{1}$ Strome College of Business, Old Dominion University, Norfolk, Virginia, USA

${ }^{2}$ Department of Medicine, Johns Hopkins School of Medicine, The Johns Hopkins University, Baltimore, Maryland, USA

${ }^{3}$ Carey Business School, The Johns Hopkins University, Baltimore, Maryland, USA

Correspondence to Dr Phillip H Phan; pphan@jhu.edu

\section{ABSTRACT}

Objectives Although JCAHO requires a standardised approach to handoffs, and while many standardised protocols have been tested, sign-out practices continue to vary. We believe this is due to the variability in workflow during inpatient duty cycle. We investigate the impact of such workflows on intern sign-out practices.

Design We employed a prospective, grounded theory mixed-method design.

Setting The study was conducted at a residency programme in the mid-Atlantic USA. Two observers randomly evaluated three types of daily sign-outs for 1 week every 3 months from September 2013 to March 2014. The compliance of each observed behaviour to JCAHO's Handoff Communication Checklist was recorded. Participants Thirty one interns conducting 134 patient sign-outs were observed randomly among the 52 in the programme.

Results In the 06:00 to 07:00 sign-back, the night-cover focused on providing information on overnight events to the day interns. In the 11:00 to 12:00 sign-out, the nightcover focused on transferring task accountability to a daycover intern before departure. In the 20:00 to 21:00 signout, the day interns focused on transferring responsibility of their patients to a night-cover.

Conclusion Different sign-out periods had different emphases regarding information exchange, personal responsibility and task accountability. Sign-outs are context-specific, implying that across-the-board standardised sign-out protocols are likely to have limited efficacy and compliance. Standardisation may need to be relative to the specific type and purpose of each sign-out to be supported by interns.

\section{INTRODUCTION}

Clinical sign-out or shift report is a multi-dimensional activity that includes the transfers of information, accountability and responsibility between healthcare providers to ensure the continuity of care and patient safety. ${ }^{1-3}$ Residents who provide primary inpatient care in academic centres experience signouts at least twice daily. The primary day team signs out to a night-coverage resident (night-cover) at the end of their day shift

\section{Strengths and limitations of this study}

- Strengths include an evidence-based and finegrained observational method to characterize the sign-out process.

- First study to contextualise sign-outs to the inpatient duty cycle.

- Data from a single site and did not include clinical outcomes are limitations.

- Type of content but not quality of information communicated (importance, relevance, priority, accuracy or completeness) was evaluated during sign-out.

and receives back their patients the beginning of the next morning shift. Residents began to experience more sign-outs when the Accreditation Council for Graduate Medical Education (ACGME) established dutyhour restrictions for residents in $2003^{4}$ that was further constrained in 2011. ${ }^{5}$ Hence, a third sign-out often occurs in which the night-cover signs out new night admissions to a day-coverage resident (day-cover) prior to departure. Anticipating risks to patient safety, the Joint Commission for Accredited Healthcare Organisations (JCAHO) introduced Goal 2E in 2006 to its National Patient Safety Goal, which required a standardised approach to handoffs. ${ }^{7}$ The resulting sign-out checklist is now the standard for evaluating sign-out quality. ${ }^{8}$ Although these recommendations established the rules of conduct for residents, the continuing low compliance is exacerbated by the lack of formal teaching on sign-outs in most medical schools and residency programs, ${ }^{9}$ and perhaps because sign-out sheets are not considered official hospital records. ${ }^{10}$

Sign-outs involve the transfers of information, accountability and responsibility for patient care, which occur at the end of the work shift. ${ }^{1-3}$ Information exchange involves 
communicating patient information to the incoming care provider, ${ }^{11}$ accountability entails the provision of a justification for actions (tasks) and decisions to another party who has an interest in these decisions ${ }^{812}$ and responsibility is an obligation created by moral or legal codes for certain behaviours, choices and decisions. ${ }^{13}$ Patient responsibility from the Physician's Charter ${ }^{14}$ includes professionalism in providing safe and competent care through 'patient ownership demanding total dedication to caring for one's patients... that includes writing orders, scheduling tests, formulating therapeutic plans, carrying out plans under the scrutiny and direction of supervisor, ....sharing patient information for team-based care' (p 231). ${ }^{15}$

Prior research has documented widespread problems with sign-out practices. ${ }^{16}{ }^{17}$ Residents are usually responsible for all patients in a service at night, many of whom they have not personally examined and are unfamiliar with plans of care established by another provider or team. ${ }^{1819}$ This lack of patient familiarity increases the risks of patient harm as covering residents may not be aware of data omissions, upcoming tasks or the potential for catastrophic events that might occur during a shift. ${ }^{18}{ }^{20}$ Discontinuities caused by frequent sign-outs can also compromise patient safety by eroding professionalism when the cross-covering physician does not experience the same depth of commitment to the primary team's patients, especially if they are overburdened with providing care for all the service's patients at night plus new overnight admissions. ${ }^{21} 22$

The literature continues to report wide variations in sign-outs. ${ }^{23}$ For example, in a nursing study, different nurses focused on different types of information during sign-out, where some provided only 'just the facts' while others were more 'professional and detailed'. ${ }^{24}$ One study found that even with a standardised sign-out protocol, the frequency of dropped tasks or missed lab and X-ray data as perceived by the night-cover and primary residents did not improve. ${ }^{25}$ Active problems, treatment plans and laboratory test results were discussed less during the night, compared with day, sign-outs. ${ }^{23}$ Day team residents often did not alert night-covers of clinical problems during sign-outs. ${ }^{26}$ The departing residents were often uncertain about the information to provide. Thus, the night-covers may be unaware of tasks they had to complete. In terms of responsibility, night-covers tend to defer to the primary teams' interpretations and plans, rather than actively ask question, since they considered themselves to be 'just covering,.$^{20}$ Consequently, $13 \%$ of the respondents in one study reported receiving incomplete handoffs with $16 \%$ of these respondents reported at least one nearmiss attributable to incomplete communication. ${ }^{19}$ In sum, the increased frequency of sign-outs from ACGME's 2011 mandate potentially increases miscommunication of patient information, incomplete transfers of accountability for tasks to be completed and disrupts professional responsibility in the physician-patient relationship. ${ }^{21}$

The objective of this study was to explore the extent to which standardised sign-outs are practiced by post-graduate first-year residents (interns) in their workflows. We conducted a grounded theory investigation using observational and interview data to hypothesise and verify participants' behaviours at sign-outs. ${ }^{27}$ The results from the grounded theory show the match between the incidents exhibited by the participants to current theory so that the latter may be modified and made relevant to how the actual work is performed. ${ }^{28}$ We explored how the sign-out dimensions of transfers of information, accountability and responsibility are expressed in the morning, mid-day and evening sign-outs. The results may explain the gap between the theory and practice of standardised sign-out.

\section{METHODS}

\section{Setting, design and participants}

The setting of this study was an Internal Medicine residency Program at a US Mid-Atlantic Academic Center with 1192 inpatient beds. Interns in the programme, from diverse backgrounds in race, national origin, age and gender were divided into four firms to care for patients who were admitted to each of the four floors in the hospital. The case-mix on each floor was similar as patients are randomly assigned, based on bed availability. Teams of five interns in a Firm worked in 5-day duty cycles to care for up to 25 inpatients a day before rotating out after 4 weeks. A weekday schedule for the interns is shown in figure 1.

All sign-outs were conducted and observed in each of the four intern offices that were converted as patient rooms with up to eight hoteling computer terminals placed close together along two walls. All sign-outs were verbally delivered face-to-face and unsupervised. The signing out (sending) intern usually read out the patients' information from the electronic health records (EHR), while the signing in (receiving) intern sometimes followed the verbal sign-out with a print-out summary of the patients' information and simultaneously referenced additional data in the patient's EHR at a neighbouring computer. Unlike Frankel's ${ }^{29}$ finding that this type of parallel process is the second most frequently observed, we found this type of sign-out interaction to be dominant in this programme.

There were three intern sign-outs each day: 06:0007:00, 11:00-12:00 and 20:00-21:00. The workflows leading to and between sign-outs for each Firm were as follows. During the overnight period from 20:00 to 06:00, the night-cover would take care of all the primary day interns' patients and receive new admissions from the ED. The first sign-out of the day occurred between 06:00 and 07:00 where the night-cover signed back patients to each of the three primary day interns. After this sign-out, the primary interns might update the information they received from the night-cover in the EHR or checked on their patients at the bedside in preparation for the 09:0011:00 morning round, while the night-cover prepared to present the overnight admissions to the attending physician at the morning round. During the morning round, 


\begin{tabular}{|c|c|c|c|c|c|c|}
\hline Hour & Activities & $\begin{array}{l}\text { Night- } \\
\text { Cover }\end{array}$ & $\begin{array}{l}\text { New } \\
\text { Night- } \\
\text { Cover }\end{array}$ & $\begin{array}{l}\text { Long } \\
\text {-Call }\end{array}$ & $\begin{array}{l}\text { Day- } \\
\text { Cover }\end{array}$ & Clinic \\
\hline $6 a$ & $\begin{array}{l}\text { Night-cover signs back patients to primary } \\
\text { interns }\end{array}$ & - & & $\longrightarrow$ & & \\
\hline 7 & \multirow{2}{*}{$\begin{array}{l}\text { Rounds with senior resident } \\
\text { on existing patients }\end{array}$} & & & & & \\
\hline 8 & & & & & & \\
\hline 9 & \multirow{2}{*}{$\begin{array}{l}\text { Rounds with attending } \\
\text { on overnight admissions }\end{array}$} & & & & & \\
\hline 10 & & & & & & \\
\hline 11 & $\begin{array}{l}\text { Night-cover signs-out overnight admissions; } \\
\text { Clinic intern signs-out }\end{array}$ & & & & 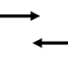 & \\
\hline $12 p-4 p$ & ED signs-out day admissions & & & $\longrightarrow$ & & \\
\hline $4 p-8 p$ & Primary interns provide care to patients & & & & & \\
\hline $8 p$ & $\begin{array}{l}\text { Primary interns sign-out \& ED sign-out 4-8pm } \\
\text { admits }\end{array}$ & & $\stackrel{\leftarrow}{\rightleftarrows}$ & - & & \\
\hline $9 p-5 a$ & ED signs out overnight admits & & $\longrightarrow$ & & & \\
\hline
\end{tabular}

Figure 1 The sign-out schedule as it relates to an intern's duty cycle. The top row refers to the time of day, key activities such as sign-out and bedside rounds and shift type. A day shift starts at 06:00 and ends at 20:00. A weekly duty cycle consists of either night-cover who starts at 20:00 and ends at 12:00, long call who takes emergency department (ED) admissions between 12:00 and 16:00, or day-cover who starts at 06:00 and takes the overnight admissions from the night-cover at 11:00 and, on the occasion when an intern has clinic consultations that week, clinic that starts at 06:00 and signs out to the day-cover at 11:00. The current Accreditation Council for Graduate Medical Education mandates a shift to be no more than 16 hours.

the attending physician and senior resident affirmed, modified or corrected the night-cover's plans of care for each overnight admission, while an intern, who would be assigned to take over the care of overnight admissions during the day (day-cover), noted the modifications or corrections in the EHR. After the morning round, the night-cover updated the tasks and plans of care for approval by the senior resident, before signing out the patients admitted at night to the day-cover. This second sign-out occurred between 11:00 and 12:00. On occasion, day interns who were assigned to clinic duties at 13:00 would also sign out their patients to the day-cover between 11:00 and 12:00. The third sign-out occurred between 20:00 and 21:00 when the primary interns signed out their patients to the incoming night-cover. Prior to this final sign-out of the day, the primary day interns updated the plans of care for their patients for approval by the senior resident. On many occasions, the night-cover might have been away from service for up to 32 hours and so may return to service at a ward consisting entirely of new patients.

Intern duty cycles were randomly observed for 1 week every 3 months from September 2013 to March 2014 to ensure that coverage of the three sign-out types were made. The interns were informed by the author (SVD) by email that a male (PHP) and female (SHL) faculty from the hospital's affiliate management school were conducting research to learn about sign-out practices. The study was approved by Johns Hopkins Medicine Institutional Review Board for verbal consent to the observations and interviews. The observers (PHP and SHL) were trained in organisational theory and research techniques and not affiliated to the training programme.
Since the observers had no clinical background, they spent a year earlier observing intern workflows and conducted pre-study interviews with senior residents, programme administrators and the director of the resident programme to understand the workflow and some terms used during sign-outs. For example, 'Active Problems' referred to patients' medical conditions indexed to their hospital admission while 'Past Medical History' were not. As the participants were new interns, both observers did not know any participants. Participants were given the opportunity to opt out of the study when the observers asked for consent to observe but no one declined.

\section{Measures}

Observations were made using the JCAHO Handoff Communication Checklist ${ }^{30}$ based on JCAHO's Goal 2E, which is considered the standard. ${ }^{8}$ This checklist followed the Situation, Background, Assessment and Recommendation (SBAR) communication structure that included such items as Patient Name, Reason for Admission, Medical History, Code Status, Active Problems, Medications, Tasks Done, Tasks to Follow-up and Contingency Plan. ${ }^{7}$ We also included the five best sign-out practices recommended by JACHO, the review of historical data, opportunity for questioning, verification of information, interactive communication and length of time for communication. We measured these items as, 'Sender Reads from Notes', 'Receiver Asks Questions', 'Receiver Reads Back Information', 'Sender Invites Questions' and 'Time Taken'. ${ }^{7}$ Each observer recorded ' 1 ' for each item observed for each patient sign-out and ' 0 ' otherwise. Observers also collected process time, using electronic stopwatches. Each observer took field notes, omitting patient identifiable information. 
Immediately after each sign-out, the observers asked the interns if they had time for a brief interview. Nine interviews were conducted across all three types of signouts using a structured 'why', 'what' and 'how' format. The purpose of the interviews was to understand the interns' decision processes and verify observers' impressions. The interviews lasted between 5 and $15 \mathrm{~min}$. One observer asked the questions while the other documented the response.

The researchers determined that a focus group discussion would be helpful to better understand the patterns observed in the data tabulated in online supplementary tables 1-3. SVD arranged the focus group discussion as a 1-hour town-hall meeting that all 52 interns attended. PHP conducted the town-hall by asking questions while SHL documented the discussions. PHP asked the following questions: 'Why are so few elements signed out at 06:00-07:00?', 'Why is the 06:00-07:00 sign-out so short?', 'Why is the 20:00-21:00 sign-out so long?', 'What is the focus of the 11:00-12:00 sign-out?' and 'What are you most worried about in your sign-outs?'.

\section{Analyses}

On the basis of the number of patients for each sign-out period, each checklist item was averaged and their percentages were compared between time periods. To assess the inter-rater agreement between the two observers for each type of sign-outs, we carried out a kappa $(\kappa)$ analysis. We also followed the Strauss and Corbin ${ }^{31}$ method of grounded theory in which content analysis is applied to all data (numerical data and interview responses) in a systematic approach to validate the constructed criteria using both directed and summative approaches. ${ }^{32} 33$ Since the aim of this study was to explore the extent to which standardised sign-outs were practiced by interns, we began our data analysis with the directed approach that applied the theory of sign-out, which comprised three dimensions pertaining to the transfers of information, responsibility, and accountability, to the SBAR structure of communication. We then used the summative approach to count and compare the data against the three sign-out dimensions to interpret the underlying context. SHL and PHP coded and analysed the numerical and interview data iteratively between themselves by working separately and jointly, until data saturation was reached. The data was grouped into three dimensions, namely transfers of information, responsibility and accountability, according to the three types of sign-outs (morning, mid-day and evening). SVD independently reviewed the results and confirmed the data structure in online supplementary table 4.

\section{RESULTS}

Table 1 provides a summary of the key findings. In total, we observed 134 patient sign-outs from 31 of the 52 interns from four, six and nine sign-outs at 06:00-07:00, 11:00-12:00 and 20:00-21:00, respectively.

The inter-rater reliability of the coding for the 06:00-07:00 sign-out was $\kappa=0.83$, where $0.61<\kappa<0.80$ was substantial agreement. ${ }^{34}$ In the morning sign-out, night-covers communicated their patients' information from the EHR $46 \%-100 \%$ of the time, while receivers recorded the information received $27 \%-100 \%$ of the time and asked questions $43 \%-54 \%$ of the time (see online supplementary table 1 ). The data suggest that the information exchange focused most frequently on the patients' active problems (73\%-93\%) overnight. Less frequent was information on the implementation of the contingency plan $(21 \%-64 \%)$, medications dispensed $(36 \%-43 \%)$, tasks completed $(14 \%-36 \%)$ or tasks to follow-up (7\%-27\%).

In discussions, interns reported that ' ... there is no need to report back on tasks done because the information is available in the EHR...' More participant quotes are

Table 1 Summary of how the three components of sign-out are manifest in each type of sign-out

\begin{tabular}{|c|c|c|c|}
\hline Sign-out type & $\begin{array}{l}\text { Information exchange } \\
\text { (for data) }\end{array}$ & $\begin{array}{l}\text { Personal responsibility } \\
\text { (for patients) }\end{array}$ & $\begin{array}{l}\text { Accountability } \\
\text { (for tasks) }\end{array}$ \\
\hline $\begin{array}{l}\text { 06:00-07:00 } \\
\text { Sign-out of night-cover to } \\
\text { primary day interns }\end{array}$ & $\begin{array}{l}\text { 1. Night-cover provides } \\
\text { information on patients' } \\
\text { condition* }^{\star}\end{array}$ & $\begin{array}{l}\text { 3. Primary day interns check if } \\
\text { to-do tasks were completed }\end{array}$ & $\begin{array}{l}\text { 2. Night-cover provides } \\
\text { information on tasks } \\
\text { completed for unexpected } \\
\text { events }\end{array}$ \\
\hline $\begin{array}{l}11: 00-12: 00 \\
\text { Sign-out of night-cover to day- } \\
\text { cover interns }\end{array}$ & $\begin{array}{l}\text { 3. Night-cover communicates } \\
\text { to-do tasks and contingency } \\
\text { plan to day-cover }\end{array}$ & $\begin{array}{l}\text { 2. Night-cover updates to-do } \\
\text { tasks and contingency plans }\end{array}$ & $\begin{array}{l}\text { 1. Night-cover presents } \\
\text { justification of to-do tasks and } \\
\text { contingency plan to attending } \\
\text { at rounds and obtains senior } \\
\text { resident endorsement before } \\
\text { sign-out }\end{array}$ \\
\hline $\begin{array}{l}20: 00-21: 00 \\
\text { Sign-out of primary day interns } \\
\text { to incoming night-cover }\end{array}$ & $\begin{array}{l}\text { 2. Primary day interns } \\
\text { communicate to-do tasks and } \\
\text { contingency plans to incoming } \\
\text { night-cover }\end{array}$ & $\begin{array}{l}\text { 1. Primary day interns prepare } \\
\text { to-do tasks and contingency } \\
\text { plans for senior resident } \\
\text { endorsement }\end{array}$ & $\begin{array}{l}\text { 3. Primary day interns } \\
\text { explain reasons for and seek } \\
\text { questions on to-do tasks } \\
\text { and contingency plans from } \\
\text { incoming night-cover }\end{array}$ \\
\hline
\end{tabular}

${ }^{*}$ Numbers refer to sequence of activities during each sign-out type. 


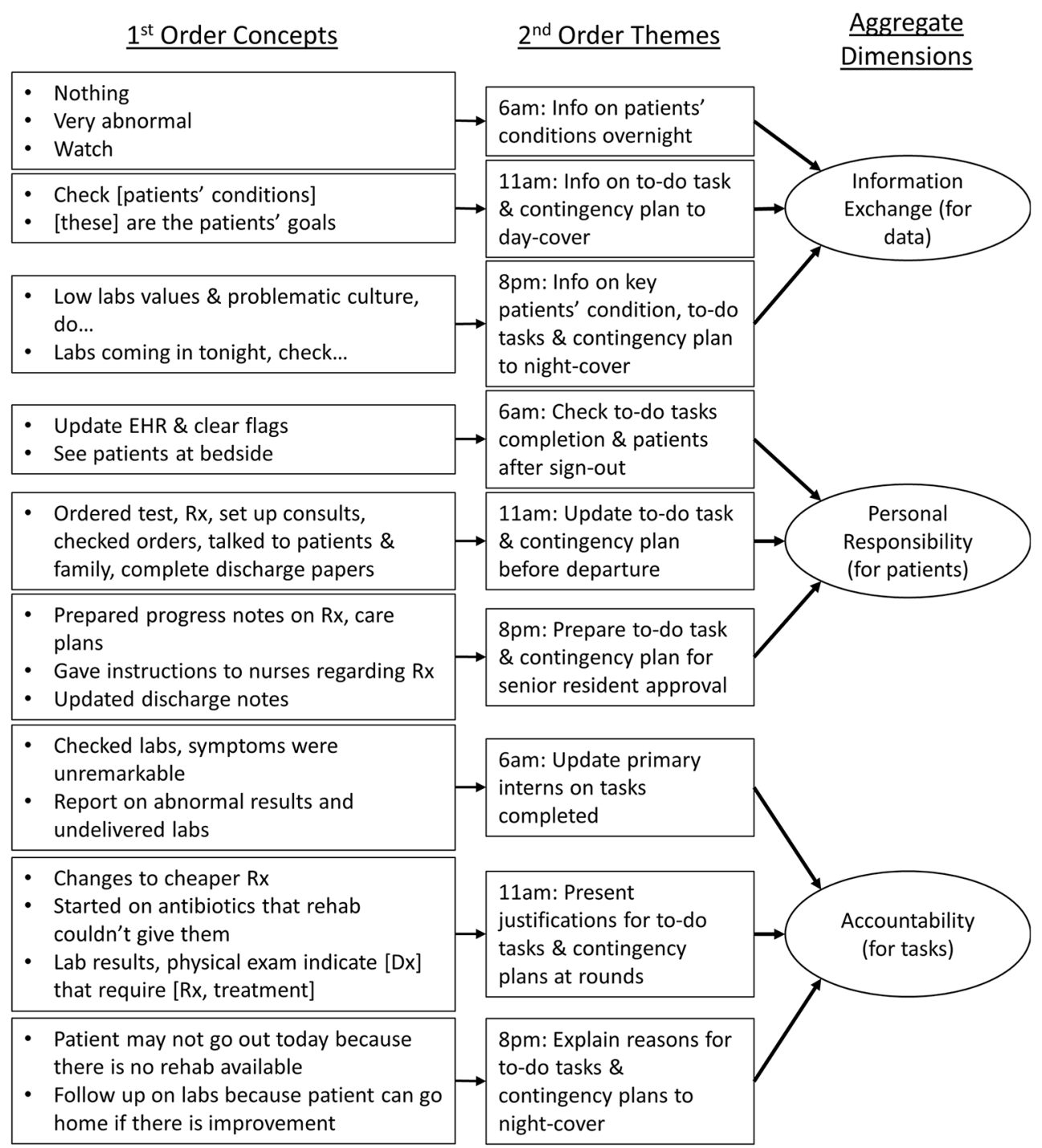

Figure 2 The data structure extracted from the observations and interviews. The left most column provides examples of the terms interns used at sign-out as observed and during the post sign-out interviews and town-hall. These are the first-order concepts that represent a summary of the raw data reported in online supplementary table 4 . The middle column refers to the concepts that most frequently appeared during each type of sign-out (ie, 06:00 sign back, 11:00 post-rounds and clinic signout and 20:00 sign-out to night-cover). The last column refers to the common elements in each types of sign-out. Therefore, Information Exchange refers to the data exchanged at each type of sign-out. Personal responsibility refers to the activities indicating behaviours related to the ownership of a patient. Accountability refers to the behaviours related to providing justification or explanations for decisions and orders.

reported in online supplementary table 4 and summarised in figure 2. Task accountability appeared to be less important than information on active problems since the information was electronically available. Discussions with interns revealed that reasons for patients' admission, medical history or code status were not communicated during the 06:00-07:00 sign-out even though these items are required by JCAHO because as the patients' primary provider, such information '...were not necessary since these are our patients and we know them...'. Thus, the transfer of responsibility to the primary team was not the focus of the 06:00-07:00 sign-out because the primary interns had the responsibility of presenting their patients during morning rounds, as shown in table 1 and figure 2.
The average time taken for morning sign-out was about $17 \mathrm{~s}$ for each patient with a modal value of $5 \mathrm{~s}$. Subsequent discussions revealed that the information exchanged in this sign-out was very brief because '...it is common for nothing to happen at night and so there's nothing to report...'. The only time a night-cover mentioned the code status to the primary intern was when the patient's family changed the code status during the night visit. Online supplementary table 1 indicates that there were improvements over time by both night-cover and primary interns in using notes during sign-outs to ensure accurate information transfer. Over time, we found that night-covers increased their frequency in reporting back overnight problems to the day teams. 
Inter-rater agreement $(\kappa=0.67)$ for the 11:00-12:00 sign-out coding was in the acceptable range. The nightcover handed over every patient who was admitted overnight to the day-cover by reading the patients' condition from the computer $100 \%$ of the time, while receivers recorded the information received in each patient's EHR $100 \%$ of the time and asked questions $78 \%-100 \%$ of the time (see online supplementary table 2 ). The information that the night-cover communicated frequently to the day-cover were follow-up tasks $(78 \%-100 \%)$ and contingency plans (89\%-100\%) for active problems $(83 \%-100 \%)$. Observations and interviews indicate that the night-covers were meticulous about completing all the tasks for their patients before departure to avoid creating ill-will with the day team. At sign-out, follow-up tasks were highlighted since lab results would be available in the afternoon, in addition to contingency plans for each patient's unique issues. The night-cover was careful to update all orders and plans of care required by the attending physician and senior residents on the EHR to ensure the transfer of professional responsibility.

Where information exchanged was concerned, the night-covers were less likely to provide information to the day-cover on their patients' reasons for admission, medical history, code status, completed tasks or tasks to follow-up, even though these were required by JCAHO. The data suggests that information exchange appeared to be the least important factor in the 11:00-12:00 sign-out. Further discussions revealed that the day-cover considered it '...unnecessary to hear all that information again during the 11:00-12:00 sign-out because the morning rounds are very detailed and the day-cover usually enters the follow-up tasks and modifications to the plans of care into the EHR during the presentation; so (we) know what needs to be done...'. Moreover, '...commonly assumed instructions are not discussed at sign-outs but only say, if a patient is not full-coded is this mentioned...'. Thus, being accountable to the day-cover to ensure that tasks were completed was of primary importance, followed by ensuring that the day-cover followed up on active problems to ensure a safe transfer of responsibility.

Inter-rater agreement $(\mathrm{K}=0.68)$ for the 20:00-21:00 sign-out was in the acceptable range. At this sign-out, the night-cover might have been away from service for up to 32 hours and could be returning to a ward of 25 unfamiliar patients. Discussions revealed that some nightcovers spent up to an hour before signing in to familiarise themselves with patients. This information was updated by the day team. Throughout the day and prior to sign-out, day interns updated each patient's EHR, 'flag' certain items for the night-cover to follow-up, prepared medication orders, contingency plans or discharge worksheets and letters, as reported in table 1 and figure 2.

The second most important sign-out activity during the 20:00-21:00 sign-out was the transfer of the most critical patient information to the night-cover. Each primary intern signed out every patient to the nightcover by reading the patients' critical information from the EHR 94\% of the time, while receivers followed the discussion from printed notes or from each patient's EHR $91 \%-96 \%$ of the time and asked questions $72 \%-80 \%$ of the time (see online supplementary table 3). Specifically, the interns provided information on the patients' active problems (91\%-94\%), their reasons for admission $(59 \%-84 \%)$, medical history $(59 \%-84 \%)$ and medications $(33 \%-47 \%)$, contingency plans $(80 \%-88 \%)$, tasks already completed $(53 \%-69 \%)$ and tasks that needed follow-up (37\%-50\%).

During the information exchange process, the day interns would provide justifications for and sought questions from the night-covers to ensure that 'to-do' tasks and contingency plans were understood, as reported in table 1 and figure 2. The information items experiencing the greatest decline in communication frequency over time were the reasons for admissions, medical history and code status. Interviews and the town-hall revealed that the interns felt such information could be found in the EHR when required and thus were not very important. As inters gained clinical experience over time, they felt more confident in their ability to select the appropriate information to transfer since '...on-call is survival time; just give us the most important information to care for the patients...'.

The town-hall also revealed that during the 20:00-21:00 sign-out, the transfer of task accountability in terms of providing justifications for to-do tasks and contingency plans became less important over time as the interns became more confident in performing tasks and implementing contingency plans and managing emergencies that might arise at night. At the beginning of the residency programme when they were inexperienced, interns exchanged a lot more information about their patients because they could not be sure what was relevant and important. As they gained experience, interns developed a mindset that they should '...just be a doctor...', implying a higher level of confidence in caring for their patients at night.

\section{DISCUSSION}

Sign-outs involve the transfers of patient information, accountability for tasks to be completed and clinical responsibility of patients from one care provider to another. In an era of limited work hours and standardised sign-outs, our findings suggest that it is more important that the information essential for each type of sign-out varies by the workflow in a duty cycle. The contextualisation of sign-out ensures that it is not burdensome and thus lead to inattention, yet complete and accurate. The results may explain some variation in the content found in earlier studies. ${ }^{24}$

Specifically, in the 06:00-07:00 sign-back, since the primary team is away from service for 10 hours, their patients' conditions may have changed overnight. Therefore, the sign back focused on changes in the status of incumbent patients. For the 11:00-12:00 sign-out between 
the night-covers and day-covers, the key to a smooth transition was for the night-cover to complete the necessary tasks before departure. Since the day-cover was present during morning rounds, task saliency and information exchange accuracy were already high. Thus, night-cover sign-outs could be made more efficient with a three-way sign-out between the night-cover, day-cover and the supervising senior resident, with the day-cover reading back to-do tasks and contingency plans to confirm understanding.

In the 20:00-21:00 sign-out, which poses the highest risks for information gaps, since the night-cover may have been away from service for a considerable period, the sign-out should be formal. The primary day team should prepare to-do tasks and contingency plans with mandatory explanations to be communicated with the tasks. The personal responsibility of the signing-out team should formally include using available data to make decisions on patients' problems and active issues to reduce critical incidents, setting priorities for acutely unwell or unstable patients to reduce the risk of overnight deterioration, knowing how to delegate certain tasks, providing specific assignments of tasks and clearly communicating the reasons for the plan of care. At the same time, the night-cover should be given a formal responsibility to study patient notes before receiving a sign-out.

This grounded theory approach to understanding the nature of sign-outs may explain why a one-size-fits-all standardised sign-out practices may not always be efficacious or efficient. Since sign-out is microsystem involving the smallest natural grouping of clinicians, typically only between the incoming and outgoing interns working together with a shared clinical purpose to provide care for a group of patients, ${ }^{29} 3536$ standardisations in sign-outs may be applied differently in different types of sign-outs. Moreover, the longitudinal observations indicate that standardisation of sign-out was also influenced by clinical experience. As the interns gained experience at the end of the year, fewer elements were communicated at signouts except ambiguous patient conditions that needed to be highlighted and watched.

A limitation of this study is that it employed observational data collection using the JCAHO Checklist at a single site. The period of observation was 9 months and did not consider clinical outcomes. These features limit predictive validity and external generalisability. Another limitation is that we did not evaluate the quality of the information (importance, relevance, priority, accuracy or completeness), only the quantity. Nevertheless, we believe that this study contributes to the sign-out literature. Nevertheless, we believe that this study makes a contribution in the sign-out literature because it highlights the contextual nature of the sign-out to explain why standardised approaches did not always work. Future studies could extend the validity and generalisability of our results using other methods of data collection, such as surveys and clinical outcomes data from the EHR from multiple sites.

\section{CONCLUSION}

Although a standardised one-size-fits-all structured sign-out process was not followed equally and similarly over all three types of sign-outs, nevertheless, a systematic microsystem of sign-out exists, as we detected some consistencies within each type of sign-out. The results indicate that interns were standardising handoff communication elements according to the workflow, patient familiarity and ownership although not always according to a standardised list of elements. The observational study suggests that a standardised sign-out for every type of sign-out is not likely to achieve compliance as each sign-out period required different types of information elements to be communicated and different focus on transfers pertaining to information exchange, accountability or responsibility. Thus, the best sign-out protocols should be sensitive to the workflow and tasks facing the residents. Appropriately emphasising the differential importance of information exchange, task accountability and personal responsibility for each type of sign-out may be a way to preserve the continuity of care.

Contributors S-HL designed the study and wrote the first draft. S-HL and PHP collected the data and completed the analyses. S-HL, PHP and SVD interpreted the data, wrote subsequent drafts and approved the manuscript for submission.

Competing interests None declared.

Ethics approval Study is approved by the Johns Hopkins Medicine Institutional Review Board. elRB: NA_00077484.

Provenance and peer review Not commissioned; externally peer reviewed.

Data sharing statement De-identified data used for the analysis is available from the first author.

Open Access This is an Open Access article distributed in accordance with the Creative Commons Attribution Non Commercial (CC BY-NC 4.0) license, which permits others to distribute, remix, adapt, build upon this work non-commercially, and license their derivative works on different terms, provided the original work is properly cited and the use is non-commercial. See: http://creativecommons.org/ licenses/by-nc/4.0/

(c) Article author(s) (or their employer(s) unless otherwise stated in the text of the article) 2017. All rights reserved. No commercial use is permitted unless otherwise expressly granted.

\section{REFERENCES}

1. Lee SH, Phan PH, Dorman T, et al. Handoffs, safety culture, and practices: evidence from the hospital survey on patient safety culture. BMC Health Serv Res 2016;16:254.

2. Jeffcott SA, Evans SM, Cameron PA, et al. Improving measurement in clinical handover. Qual Saf Health Care 2009;18:272-6.

3. Manser T, Foster S, Gisin S, et al. Assessing the quality of patient handoffs at care transitions. Qual Saf Health Care 2010;19:e44.

4. Directory of Graduate Medical Education Programs, 2003-2004 Chicago, IL: American Medical Association Press, 2003.

5. Graduate Medical Education Directory, 2011-2012. Chicago, IL: American Medical Association Press, 2011.

6. Jagsi R, Weinstein DF, Shapiro J, et al. The Accreditation Council for Graduate Medical Education's limits on residents' work hours and patient safety. Arch Intern Med 2008;168:493-500.

7. Joint Commission Perspectives on Patient Safety. Improving handoff communications: meeting national patient safety goal $2 E$. : Joint Commission Resources, 2006:6: 9-15.

8. Patterson ES, Wears RL . Patient handoffs: standardized and reliable measurement tools remain elusive. Jt Comm J Qual Patient Saf 2010;36:52-61.

9. Horwitz LI, Krumholz HM, Green ML, et al. Transfers of patient care between house staff on internal medicine wards: a national survey. Arch Intern Med 2006;166:1173-7. 
10. Stein DM, Stetson PD. Time to sign off on signout. Acad Med 2011;86:804-6.

11. Arora $\mathrm{V}$, Johnson $\mathrm{J}$, Lovinger $\mathrm{D}$, et al. Communication failures in patient sign-out and suggestions for improvement: a critical incident analysis. Qual Saf Health Care 2005;14:401-7.

12. Tetlock PE. Accountability: the neglected social context of judgment and choice. Res Org Behav 1985;7:297-332.

13. Schlenker BR, Britt TW, Pennington J, et al. The triangle model of responsibility. Psychol Rev 1994;101:632-52.

14. ABIM Foundation. American Board of Internal MedicineACP-ASIM Foundation. American College of Physicians-American Society of Internal MedicineEuropean Federation of Internal Medicine. Medical professionalism in the new Millennium: a physician charter. Ann Intern Med 2002;136:243-6.

15. Van Eaton EG, Horvath KD, Pellegrini CA. Professionalism and the shift mentality: how to reconcile patient ownership with limited work hours. Arch Surg 2005;140:230-5.

16. Joint Commission. Sentinel event data - Root causes by event type. 2014 http://www.jointcommission.org/Sentinel_Event_Statistics/.

17. Mardis M, Davis J, Benningfield B, et al. Shift-to-Shift handoff effects on patient safety and outcomes. American Journal of Medical Quality 2017;32:34-42.

18. Borowitz SM, Waggoner-Fountain LA, Bass EJ, et al. Adequacy of information transferred at resident sign-out (in-hospital handover of care): a prospective survey. Qual Saf Health Care 2008;17:6-10.

19. Hinami K, Farnan JM, Meltzer DO, et al. Understanding communication during hospitalist service changes: a mixed methods study. J Hosp Med 2009;4:535-40.

20. Horwitz LI, Moin T, Krumholz HM, et al. What are covering doctors told about their patients? analysis of sign-out among internal medicine house staff. Qual Saf Health Care 2009;18:248-55.

21. Arora VM, Johnson JK, Meltzer DO, et al. A theoretical framework and competency-based approach to improving handoffs. Qual Saf Health Care 2008;17:11-14.

22. Bellini L. Off-hours care: not so off. J Hosp Med 2011;6:3-4.
23. Helms AS, Perez TE, Baltz J, et al. Use of an appreciative inquiry approach to improve resident sign-out in an era of multiple shift changes. J Gen Intern Med 2012;27:287-91.

24. Staggers N, Jennings BM. The content and context of change of shift report on medical and surgical units. J Nurs Adm 2009;39:393-8.

25. Salerno SM, Arnett MV, Domanski JP. Standardized sign-out reduces intern perception of medical errors on the general internal medicine ward. Teach Learn Med 2009;21:121-6.

26. Scoglietti VC, Collier KT, Long EL, et al. After-hours complications: evaluation of the predictive accuracy of resident sign-out. Am Surg 2010;76:682-6.

27. Glaser B. Basics of grounded theory analysis: emergence vs forcing. Mill Valley, CA: Sociological Press, 1992.

28. Glaser BG, Strauss AL. The discovery of grounded theory: strategies for qualitative research. New Brunswick: Aldine Transaction, 1967.

29. Frankel RM, Flanagan M, Ebright $P$, et al. Context, culture and (non-verbal) communication affect handover quality. BMJ Qual Saf 2012;21 Suppl 1(Suppl 1):i121-i128.

30. Joint Commission Resources. Improving hand-off communication, 2007.

31. Strauss A, Corbin J. Basics of qualitative research: techniques and procedures for developing grounded theory. 2nd edn. Thousand Oaks: Sage, 1998.

32. Charmaz K. Constructing grounded theory. London: Sage, 2006.

33. Hsieh HF, Shannon SE. Three approaches to qualitative content analysis. Qual Health Res 2005;15:1277-88.

34. Landis JR, Koch GG. The measurement of observer agreement for categorical data. Biometrics 1977;33:159-74.

35. Batalden PB, Nelson EC, Edwards WH, et al. Microsystems in health care: part 9. developing small clinical units to attain peak performance. Jt Comm J Qual Saf 2003;29:575-85.

36. Nelson EC, Batalden PB, Huber TP, et al. Microsystems in health care: part 1. Learning from high-performing front-line clinical units. Jt Comm J Qual Improv 2002;28:472-93. 